\title{
Can remote ischemic preconditioning counteract the renal functional deterioration attributable to partial nephrectomy under warm ischemia? Results of an animal study
}

Tuna Till Mut ${ }^{1 *}$ DD, Ömer Acar ${ }^{2}$, Ayse Armutlu ${ }^{3}$, Said Incir ${ }^{4}$, Annemarie Uhlig ${ }^{1}$, Lale A. Ertuglu ${ }^{5}$, Melis Özel ${ }^{5}$, Ali Cihan Taskin ${ }^{6}$, Dilek Ertoy Baydar ${ }^{3}$, Mehmet Kanbay $^{7}$ and Tarık Esen ${ }^{2,8}$

\begin{abstract}
Background: To investigate if remote ischemic preconditioning (RIPC) can offer any renoprotective value by counteracting the deleterious effect of partial nephrectomy (PN) under warm ischemia on renal function.

Methods: Four groups, each with 5 Wistar albino rats, were constructed; RIPC + PN, PN, RIPC and sham. Right nephrectomy was performed to constitute a solitary kidney model. RIPC denoted sequential clamping/declamping of the femoral artery/vein complex. PN was performed under warm-ischemia following RIPC. Blood samples were collected on multiple occasions until euthanasia on day 7.

Immunoassays were conducted to measure the serum and tissues levels of kidney injury markers. Kidneys were examined histologically and morphometric analyzes were performed using digital scanning.

Results: IL-33 levels did not differ significantly between the groups. Serum levels of KIM-1, NGAL, and aldose reductase in RIPC + PN, PN and RIPC groups were significantly lower than that of sham group. Tissue biomarker levels were similar across groups.

The observed trend in mean necrosis area of PN group was higher than that of RIPC + PN group $(p>0.05)$. The transitional zone between necrosis and healthy tissue showed a trend towards increasing width in the rats subjected to RIPC before PN vs. those who underwent PN without RIPC ( $p>0.05)$.
\end{abstract}

Conclusion: RIPC failed to counteract the renal functional consequences of PN under warm ischemia in a solitary kidney animal model. The supportive but marginal histological findings in favor of RIPC's renoprotective potential were not supplemented with the changes in serum and tissue biomarker levels.

Keywords: Kidney, Ischemia, Function, Preconditioning, Remote, Biomarker

\footnotetext{
* Correspondence: ttmut@outlook.com; tuna.mut@med.uni-goettingen.de 'Department of Urology, University Medical Center Göttingen, Robert-Koch Straße 40, 37075 Göttingen, Germany

Full list of author information is available at the end of the article
}

(c) The Author(s). 2021 Open Access This article is licensed under a Creative Commons Attribution 4.0 International License, which permits use, sharing, adaptation, distribution and reproduction in any medium or format, as long as you give appropriate credit to the original author(s) and the source, provide a link to the Creative Commons licence, and indicate if changes were made. The images or other third party material in this article are included in the article's Creative Commons licence, unless indicated otherwise in a credit line to the material. If material is not included in the article's Creative Commons licence and your intended use is not permitted by statutory regulation or exceeds the permitted use, you will need to obtain permission directly from the copyright holder. To view a copy of this licence, visit http://creativecommons.org/licenses/by/4.0/. The Creative Commons Public Domain Dedication waiver (http://creativecommons.org/publicdomain/zero/1.0/) applies to the data made available in this article, unless otherwise stated in a credit line to the data. 


\section{Background}

Partial nephrectomy (PN) is the preferred surgical treatment modality for localized renal tumors [1]. PN is commonly performed under warm-ischemic conditions in an effort to provide a relatively "bloodless" surgical field which will facilitate complete excision of the mass and subsequent reconstruction of the tumor bed. However, temporary interruption of the renal blood flow can be a predisposing factor for de-novo chronic kidney insufficiency [2]. For this reason, it is recommended that the ischemic duration should be limited to 20-30 min [3].

Ischemic preconditioning (IPC) is an innate tissue adaptation mechanism whereby repeated brief ischemia episodes trigger local and/or remote organ protection against succeeding exposure to the same or other type of injury $[4,5]$. Local IPC has been mainly investigated in animal studies with varying degrees of success and owing to the technical limitations related to the extrapolation of local preconditioning methodology to clinical setting, further studies were concentrated around its remote counterpart $[6,7]$.

Remote ischemic preconditioning (RIPC) has been postulated as a measure that might potentially reverse or minimize the ischemia/reperfusion-related functional insult involving various organs. It has been defined as repeated brief ischemia episodes at a remote site before an anticipated ischemia/reperfusion injury of the target organ. An IPC regimen applied only 5 min prior to warm ischemia has been shown to offer significant protection against renal functional impairment in rats [8]. However, no consensus exists regarding the optimal durations of the preconditioning protocol itself and the latent period after which IPC exerts its beneficial effect. Several studies focused on the renoprotective effect of RIPC, which would theoretically enable prolongation of the ischemic duration within the context of $\mathrm{PN}$, especially while treating renal masses with complex morphometric features [6]. However, relying on markers with poor specificity (such as serum creatinine level) while assessing the renal functional changes attributable to RIPC and/or performing the experiment in the presence of two functioning kidneys plagued the interpretation and utility of their findings potentially in favor of RIPC [9-11].

Several novel biomarkers of acute kidney injury (AKI) have been introduced for diagnostic and predictive purposes and these might be of greater value while testing how RIPC influences renal function, as subtle changes would remain undetectable by biomarkers with higher signaling threshold [12]. KIM-1 and NGAL are inducible biomarkers, with significantly increased levels as a direct response to nephron damage [13, 14]. KIM-1, in particular, is activated after epithelial injury and is thought to play a role in tubular regeneration process. It has been demonstrated that NGAL concentrations, in both serum and urine, increased promptly, within hours of ischemia and nephrotoxic insult [15]. IL-33 is an acute inflammatory marker and it has been shown that anti-inflammatory drugs could inhibit renal damage by reducing the expression of IL-33, which supports its value as a marker of AKI [16]. Ischemia driven aldose reductase overexpression in renal tissue has been demonstrated to be an important step in the pathogenesis of CKD [17].

In light of these data, we aimed to assess the impact of RIPC on renal functional preservation in a solitary kidney PN model by incorporating the data gathered by more sensitive and specific biomarkers of kidney injury in addition to histological analysis.

\section{Methods}

The study was approved by Local Ethics Committee for Animal Experiments of Koc University (Approval no: 2015-19). The animals were kept in Koç University Animal Research Facility of Center for Translational Medicine (KUTTAM) under $12 \mathrm{~h}$ light-12 h dark cycle, and a diet of commercial pellet food ad libitum and automatic water containers were provided. Twenty-Five Wistar albino rats were included. The first 5 animals were used for the pilot study in which procedural steps were tested. The remaining 20 animals were divided into 4 groups: sham, RIPC, RIPC + PN, and PN.

\section{Surgical procedures}

Anesthesia was induced by intraperitoneal injection of Ketamine $(70-100 \mathrm{mg} / \mathrm{kg}$ ) and Xylazine $(5-10 \mathrm{mg} / \mathrm{kg})$. This allowed us an operating time of maximum $90 \mathrm{~min}$ which included the surgical intervention itself (skin-toskin) and optimal recovery from anesthesia. Surgeries were performed transperitoneally through a flank incision under aseptic conditions, right nephrectomy was performed in all groups except the sham group. Three days later, PN was performed in the PN and RIPC + PN groups. PN denoted wedge resection of a left renal parenchymal island with a scalpel under warm-ischemic conditions (Fig. 1a). Mean excised kidney tissue volume was 2 $\mathrm{mm}^{3}$. In the RIPC + PN group, RIPC preceded PN by 30 min and was employed via sequential clamping / declamping of the femoral artery/vein complex, which was repeated 4 times, each cycle lasting $1 \mathrm{~min}$ (Fig. 1b). Warm ischemia was constituted by en-bloc clamping of the renal pedicle for a mean duration of $213 \pm 67 \mathrm{~s}$. Renal vessels were freed after securing hemostasis by selective probe electrocauterization of the bleeding spots in the tumor bed. All of the surgical interventions were performed on a heating plate to prevent hypothermia. The sham group underwent laparotomy twice (on days 1 and 3 ).

Blood samples were drawn from the tail vein, as depicted in the following timeline; at the beginning of the experiment prior to the right nephrectomy, on the 


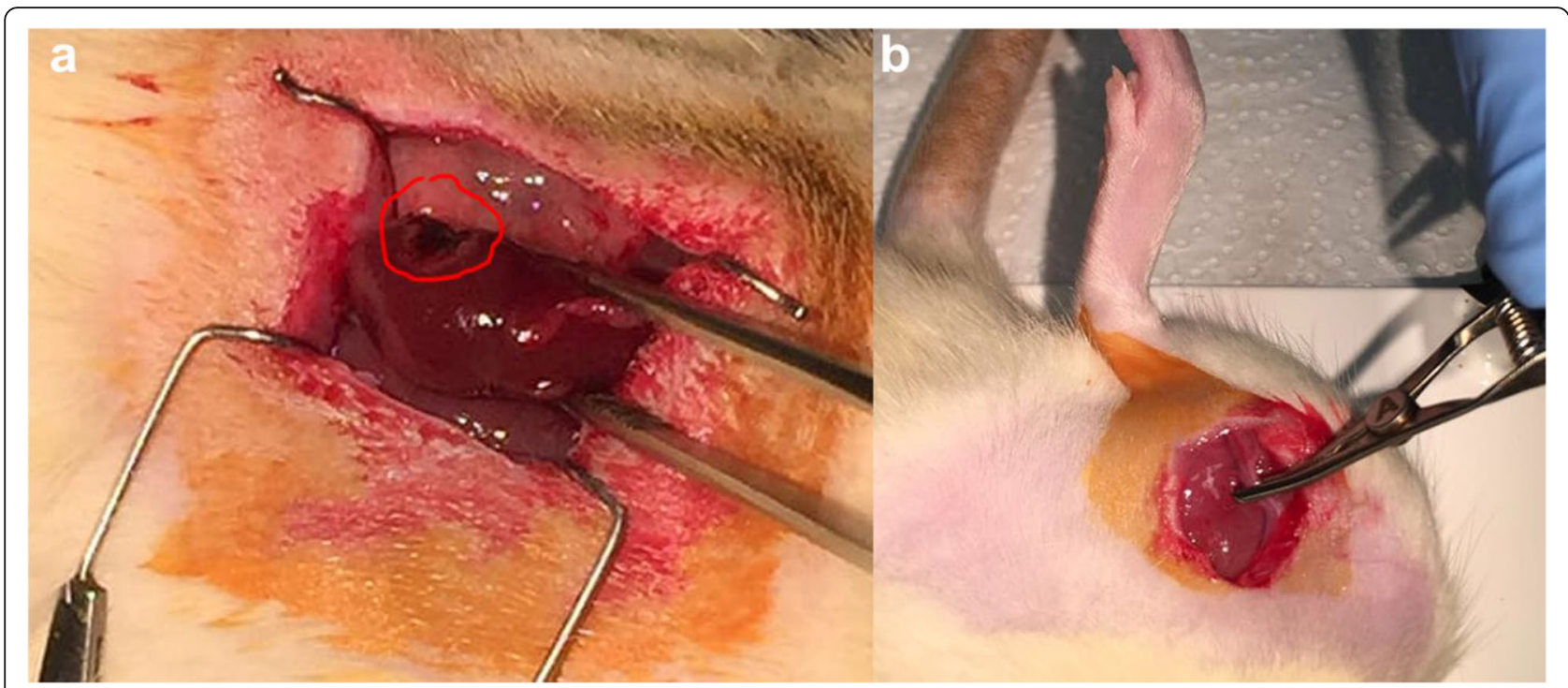

Fig. 1 a Macroscopic view of the left kidney s/p PN. Red-encircled area is showing the resultant parenchymal defect. b Clamping phase of the RIPC cycle. Femoral blood flow (artery and vein) was temporarily interrupted by bulldog clamp

3rd day of the experiment prior to RIPC and/or PN and every $24 \mathrm{~h}$ thereafter, until euthanasia on day 7 by cervical dislocation under general anesthesia induced by intraperitoneal injection of Ketamine $(70-100 \mathrm{mg} / \mathrm{kg})$ and Xylazine (5-10 mg/kg) (Fig. 2) [5]. Following euthanasia, left kidneys were extracted and cut in half along the sagittal axis. One half was put into $10 \%$ buffered formalin and submitted to pathology lab for histological analysis. Remaining kidney tissue and blood samples were stored at $-80{ }^{\circ} \mathrm{C}$ for biochemical investigations. Previously excised right kidney specimens were treated in the same manner. Weight measurement and assessment of nutritional and hydration status were conducted at each blood draw session.

\section{Immunoassays of blood-based biomarkers}

Neutrophil gelatinase-associated lipocalin (NGAL) and Kidney Injury Molecule-1 (KIM-1) levels in serum samples and kidney tissue specimens were determined by SandwichELISA using commercial kits (Boster, Pleasanton, USA). Limits of detection (LOD) were, $<10 \mathrm{pg} / \mathrm{ml}$ and $<2.0 \mathrm{pg} / \mathrm{ml}$ for the NGAL and KIM-1, respectively.

Sandwich-ELISA commercial kits were used to determine the serum and kidney tissue levels of IL-33 (R\&D Systems, Minneapolis, USA) and aldose reductase (MyBiosource, San Diego, USA). LODs were, $2.8 \mathrm{pg} / \mathrm{ml}$ and $<0.19 \mathrm{ng} / \mathrm{ml}$ for the IL-33 and aldose reductase, respectively.

Serum creatinine levels were measured with Creatinine Colorimetric Assay Kit (Cayman, Michigan, USA) based on Jaffe's reaction. LOD was $0.1 \mathrm{mg} / \mathrm{dl}$ for the creatinine assay.

All parameters measured with ELISA were studied in duplicate.

Kidney tissues were homogenized in $100 \mathrm{mmol} / \mathrm{L}$ phosphate buffer ( $\mathrm{pH}:$ 7.4) containing sodium azide $(0.05 \%)$ for $1 \mathrm{~min}$ on ice and then centrifuged at $20.000 \mathrm{~g}$ at $+4{ }^{\circ} \mathrm{C}$ for $15 \mathrm{~min}$ and supernatants were obtained.
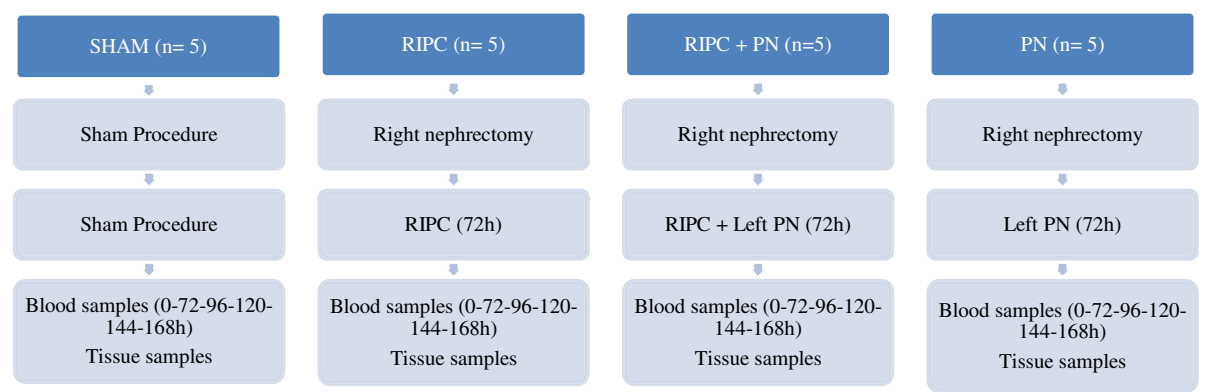

Fig. 2 The study protocol: Four groups, each with 5 Wistar albino rats, were constructed; RIPC + PN, PN, RIPC, and sham. Right nephrectomy was performed in all groups except the sham group. Three days later, PN was performed in the PN and RIPC + PN groups. PN was performed under warm ischemia following RIPC. Blood samples were collected on multiple occasions until euthanasia on day 7 


\section{Histopathological examination}

Following overnight fixation in $10 \%$ formalin at room temperature, kidney tissues were subjected to routine paraffin embedding procedure. Five sections of $2 \mu \mathrm{m}$ thick and at $5 \mu \mathrm{m}$ intervals were obtained from the paraffin blocks. Initial slides were stained with hematoxylin and eosin (H\&E) on Sakura Tissue-Tek Prisma automated slide stainer (Nagano, Japan). Remaining 4 were used for additional histochemical stainings with Jones' methenamine silver (JMS) and periodic acid-Schiff (PAS) methods in order to provide a better assessment of morphology and the extent of histological changes. All light microscopic evaluations were carried out using Olympus BX53 optical microscope. Areas of necrosis and thickness of the zone of severe ischemia were measured for comparison between groups. Measurements were accomplished on digital slides scanned at 40X by Philips IntelliSite Ultra Fast Scanner NOCTN442 (Amsterdam, Netherlands) using the drawing line and area measurement tools of the Image Management System Software (version 3.3.1) (Royal Philips Healthcare, Amsterdam, Netherlands) (Fig. 3c-d). Five $\mu \mathrm{m}$ apart 5 slides (4 special stains and 1 H\&E) from each kidney were scanned, area and thickness measurements were done in each section, and average numbers were obtained for each rat.

The hydropic degeneration of the tubular epithelium, single cell tubular necrosis, cast formations and focal
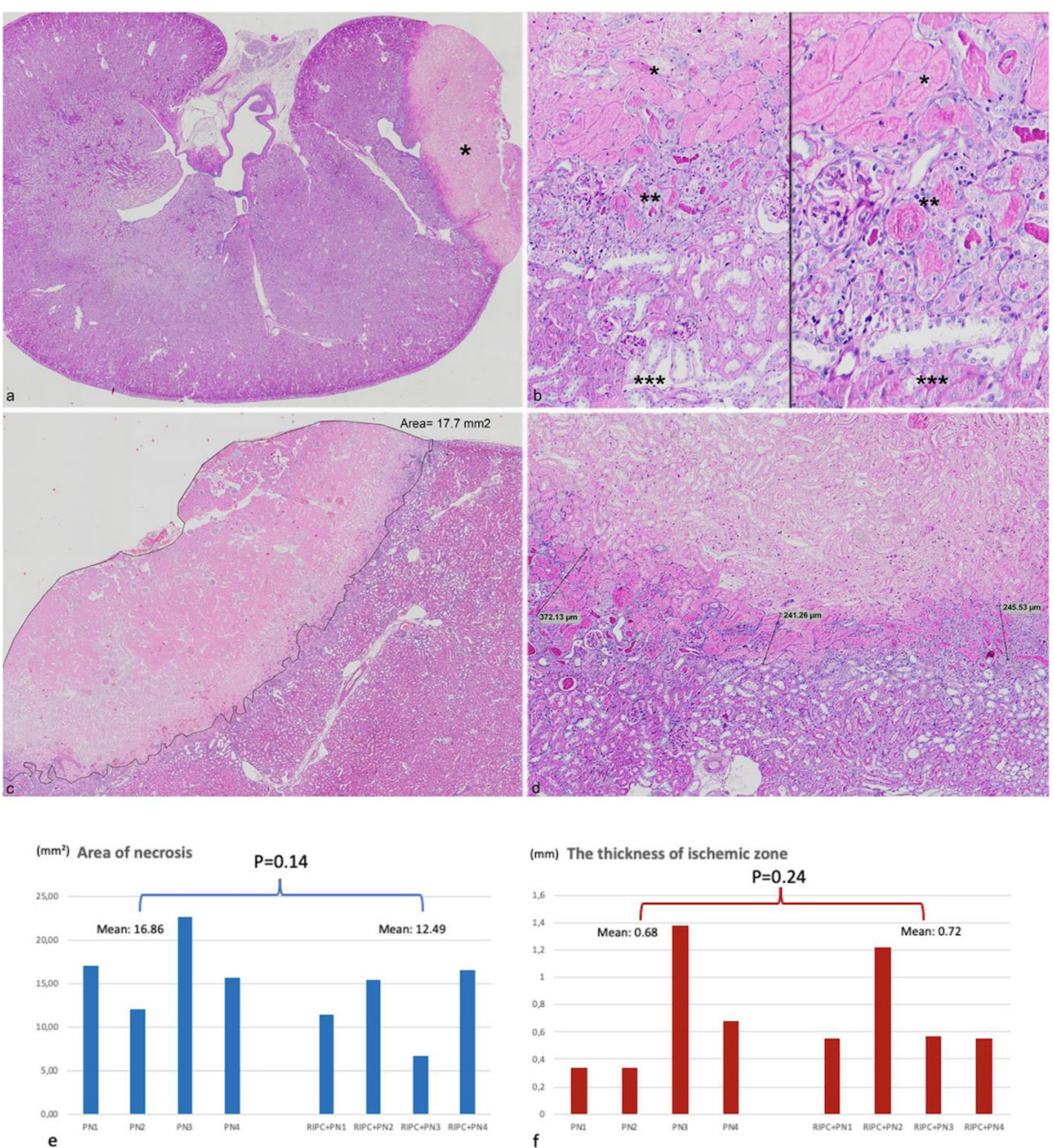

Fig. 3 a One of the rat kidneys in PN group showing focal infarct (depicted by *) at the resection bed (H-E x 15). $\mathbf{b}$ Zone of severe ischemia (depicted by ${ }^{*}$ ) between regions of infarct (depicted by *) and unaffected renal parenchyma (depicted by ***) (Left: PAS x 100; Right: PAS $x$ 200). $\mathbf{c}$ and $\mathbf{d}$ Calculations done by the image analysis program. Panel $\mathbf{C}$ shows the encircled and measured area of necrosis, while panel $\mathbf{D}$ demonstrates the thickness readings of ischemic zone through the perpendicular lines drawn $1 \mathrm{~mm}$ apart throughout the entire lesion (A: H-E X 30; B: PAS $\times 90$ ). e Area of necrosis in PN and RIPC + PN groups (each blue bar indicating a rat belonging to the groups being compared, $\mathrm{p}=$ 0.14). $\mathbf{f}$ The thickness of ischemic zone in PN and RIPC + PN groups (each red bar indicating a rat belonging to the groups being compared, $p=0.24)$ 
interstitial inflammation were scored from 0 to 2 taking into account the frequency of the lesions as 0 , none; 1 , rare; and 2, common (presence of at least one group of tubules with the lesion on $1 \mathrm{~mm}^{2}$ of area).

\section{Immunohistochemistry}

An immunohistochemical staining for $\mathrm{Ki}-67$ was performed to evaluate the regenerative/proliferative activity of the tubular epithelial cells. The BenchMark Ultra automated staining platform (Ventana Medical System, Inc., USA) was used for this purpose. Briefly, the tissue sections from the representative paraffin blocks that were cut at $3 \mu \mathrm{m}$ thickness onto charged slides were deparaffinized with EZ Prep. solution (Ventana medical system, cat. no: $950-102$ ) at $75^{\circ} \mathrm{C}$. Following rehydration through alcohol series and 32 min heat-induced epitope retrieval at $100{ }^{\circ} \mathrm{C}$ with an EDTA-based buffer (Cell Conditioner 1, Ventana; cat. no: 950-124), tissue sections were incubated for $32 \mathrm{~min}$ with anti-Ki-67 primary antibody (Ventana; pre-diluted; monoclonal rabbit, clone SP6) at $37^{\circ} \mathrm{C}$ temperature. Washing between the steps were accomplished by Reaction Buffer (Ventana medical system, cat. no: 950-300). Ultra View Detection kit (Ventana medical system, cat. no: 760-500) was used for the detection of the target protein. The reaction product was visualized with $3,3^{\prime}$-diaminobenzidine chromogen and counterstaining with hematoxylin was done. Nuclear staining was considered positive. Appropriate staining of the germinal centers of normal tonsil served as a positive control. Ki-67 index was expressed as the percentage of the number of immunostained nuclei among the total number of tubular cell nuclei.

\section{Statistical analyses}

Statistical comparisons of categorical variables were performed using the chi [2]-test. Continuous variables were compared using Student's t-test or the Wilcoxon rank sum test depending on whether the data was normally distributed or not. For continuous-paired data, the Wilcoxon signed rank test was used. Longitudinal analyses were performed using linear mixed effect models. All tests were 2 -sided, the alpha level for statistical significance was set at 0.05 . Statistical analyses were performed with R Statistical Software version 3.6.3 (Foundation for Statistical Computing, Vienna, Austria).

The main reference group was the sham group but in order to account for all possible differences between the study groups and do bidirectional crosscheck, each group has been used once as the reference group.

\section{Results}

In the pilot study, we had no subject loss, but in the actual study one of the rats in the PN group died after the first blood draw (before any surgical procedure). As a result, our mortality rate was calculated to be $5 \%$.

At the start of the study, no statistically significant difference was noted between the study groups in terms of mean body weight, with the overall mean value being $312 \pm 32 \mathrm{~g}$. Mean weight loss in the RIPC $(22 \pm 12.55 \mathrm{~g})$ and RIPC + PN $(20.8 \pm 11.17 \mathrm{~g})$ groups was significantly more than that recorded in the sham group $(1.2 \pm 11.97$ g) $(p<0.001)$.

The intra- and inter-coefficient of variabilities (CV) were 4.5 and $6.1 \%$ for NGAL, 4.2 and $6.2 \%$ for KIM-1, $5.3 \%$ and 5.0 for IL-33, $\leq 8.0 \%$ and $\leq 10.0 \%$ for aldose reductase, were 6.4 and $4.6 \%$ for creatinine, respectively.

Regarding IL-33 values, there was no statistically significant difference between the groups. However, mean IL-33 value of the RIPC + PN group was significantly lower than that of the RIPC group $(p<0.05$, Fig. 4). Likewise, the reduction detected in mean NGAL values of the RIPC + PN group reached statistical significance when compared to the sham and RIPC groups $(p<0.01$, Fig. 4). Mean values of KIM-1 and aldose reductase were significantly lower in the RIPC + PN group with respect to that of the sham group $(p<0.05$ and $p<0.001$, respectively, Fig. 4). In addition, there was a statistically significant difference between the sham and PN groups in terms of the aldose reductase level $(\mathrm{p}<0.05$, Fig. 4). Creatinine levels demonstrated an increase along the course of the study in all groups when compared with the trend noted in the sham group (Fig. 4). However, this difference was significantly different only between the RIPC and sham groups $(p<0.05)$.

The tissue levels of the biomarkers measured in the left and right kidney specimens exhibited insignificant differences across study groups. In order to control for the effect of the experimental procedures as a whole, we also measured the difference between the right and left kidney specimens in terms of biomarker levels, which similarly revealed statistically insignificant results.

Microscopic examination showed ischemic necrosis (i.e. infarct) in the RIPC $+\mathrm{PN}$ and PN groups, at the area of PN (Fig. 3a). There was also a severe ischemic zone between the necrotic area and viable kidney tissue (Fig. 3b).

Regarding the outcome of morphometric analyses; area of total infarct, seen at the resection bed of PN, was larger in the PN group (mean: $16.86 \mathrm{~mm}^{2}$ ) when compared to the RIPC + PN group (mean: $12.49 \mathrm{~mm}^{2}$ ), yet the difference did not reach the level of significance $(p>0.05)$. Mean width of the transitional ischemic zone, the area between the infarcted and viable renal tissue, was similar in both groups, $0.72 \mathrm{~mm}$ and $0.68 \mathrm{~mm}$ in the RIPC + PN and PN sets, respectively $(\mathrm{p}>0.05)$. Ki-67 proliferative index was $2 \%$ in both groups. 


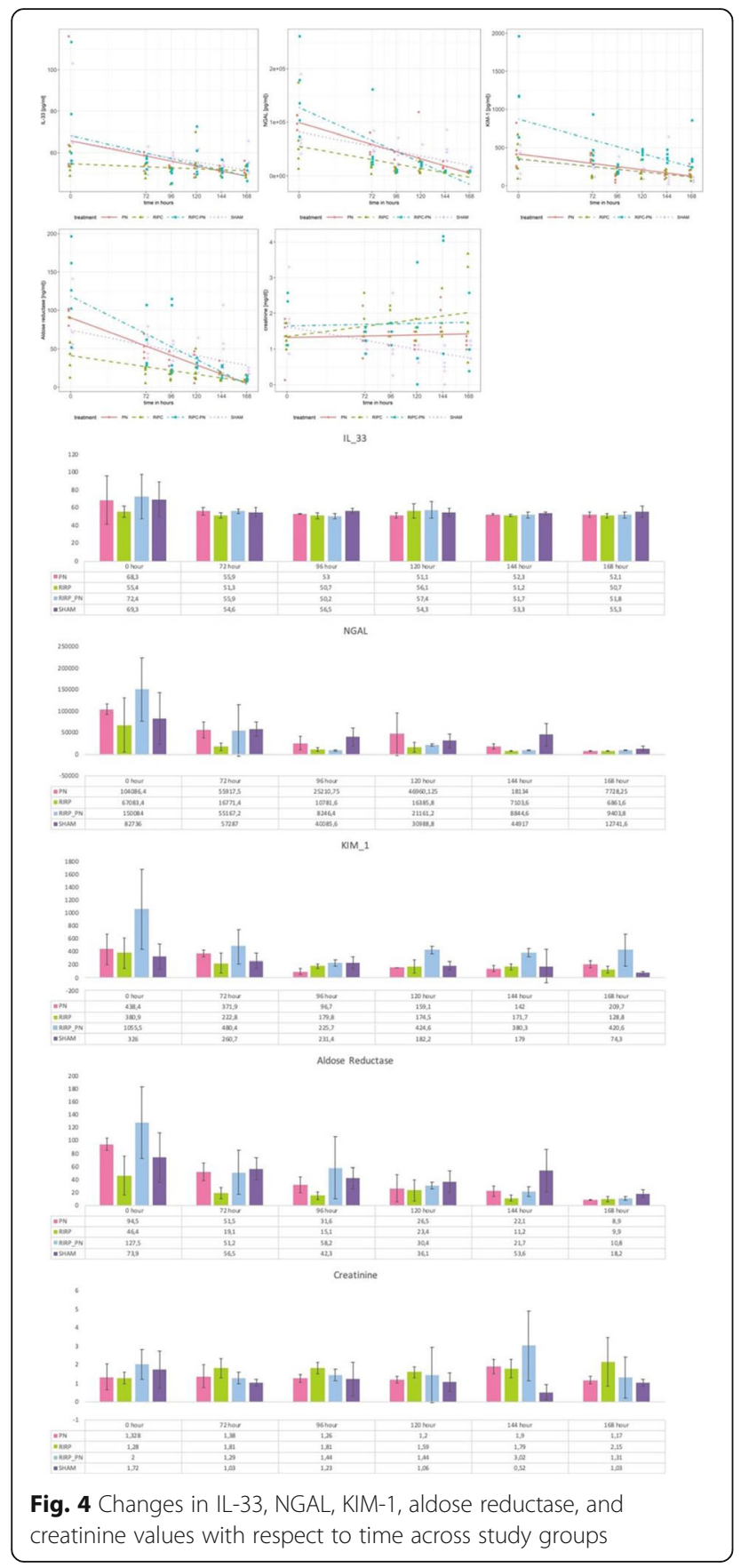

No difference was detected in terms of hydropic degeneration of tubular epithelium, single cell necrosis, cast formations or interstitial inflammation between study groups.

\section{Discussion}

The main functional goals of $\mathrm{PN}$ are to preserve as much normal tissue as possible without violating oncological principles and to avoid prolonged warm ischemia. Despite all the efforts, a functional decline in the range of $20 \%$ is anticipated early after PN. The importance of parenchymal preservation is more pronounced in the setting of imperative or absolute PNs. A retrospective study involving 360 patients with solitary kidneys showed a $6 \%$ increase in the incidence of de-novo severe chronic kidney disease (CKD) with each additional minute of warm ischemia. CKD risk was even greater for renal masses with complex morphometric features which would necessitate longer on-clamp duration for a proper PN. In addition, CKD has been shown to be a strong predictor of cardiovascular events and associated mortality in the long run $[18,19]$.

Several different technical modifications were introduced in an effort to shorten the duration and minimize the functional consequences of warm ischemia time (WIT) during PN, including early unclamping, renal hypothermia, segmental artery clamping and zeroischemia technique [20-23]. However, data regarding their actual influence on functional and perioperative outcomes is conflicting. Early hilar unclamping was found to be associated with increased blood loss and longer operative duration when compared to the standard approach [24]. Studies about intraoperative cold ischemia showed inconsistent results, with marginal functional benefits only in diabetic and hypertensive patients [25]. The zero-ischemia technique, which involves meticulous dissection of the renal vasculature, was found to be too laborious from the technical standpoint which limited its application to high-volume surgeons.

The need for a simple, effective and reproducible method which could augment the resilience of renal parenchyma against the ischemic insult related to the WIT of PN is currently unmet. RIPC may serve well to fill this gap as it was shown to encompass the potential to promote renoprotection in instances which might indirectly endanger kidney function, such as cardiovascular surgery. Repetition of brief ischemia and reperfusion episodes remotely may result in enhanced tolerance of the kidney to the anticipated, subsequent ischemic damage [26]. This concept was proven by Huang et al., who became the first to demonstrate that remote myocardial preconditioning not only decreased the myocardial infarct area, but also reduced the severity of kidney injury [26]. However, subsequent human and small-animal studies, concentrating on the relationship between RIPC and reversal of acute kidney injury (AKI), revealed somewhat disappointing results [27, 28]. Bedir et al. tested the renoprotective value of RIPC in a porcine solitary kidney model [11]. Their modified study design, which included larger kidneys with a potentially better analogy to human counterparts and a solitary kidney model that eliminated the confounding effect of contralateral kidney on functional analysis, was deemed insufficient to disprove the negative outcomes obtained in prior RIPC studies. 
Nevertheless, using serum creatinine to monitor functional changes in the kidneys that were subjected to RIPC was their major limitation, as creatinine has poor sensitivity in detecting AKI [29]. Huang et al. tried to overcome the drawbacks of creatinine-based assessment by measuring urinary retinol binding protein levels as a measure of glomerular filtration rate [10]. In their study involving 82 patients, they showed that transient lower limb ischemia reduced renal impairment in the shortterm but failed to provide a similar benefit in the long run, despite a positive but statistically insignificant trend in favor of RIPC. However, their outcomes would have been more supportive of RIPC, should they limited their analysis to patients with solitary kidney, which is hard to implement and standardize in a study involving human subjects.

As expected, creatinine levels showed a consistent rise in all groups except the sham group. When compared to the trend observed in the sham group, serum levels of the other biomarkers paradoxically declined along the time course of the study. Inappropriate timing of RIPC and/or PN or the inadequacy of the time interval spent between right nephrectomy and the other experimental procedures might be the underlying reasons for this controversy. We could have shown a more profound protective effect of RIPC if we had proceeded with PN after a longer period of time, allowing the study subjects to show sufficient reaction to the intervention being tested [30]. However, the same trend was also evident for the groups who did not undergo RIPC. Moreover, conducting the pre- and post-intervention follow-up of the rats in the absence of metabolic cage might have influenced their kidney function. Undoubtedly, measuring the urinary levels of these biomarkers, lack of which is a drawback of this study, would have served to strengthen the accuracy of analysis. Lastly, small sample size together with a mortality rate of $5 \%$ decreased the power of statistical testing and could be considered as another limitation.

Although we were unable to demonstrate a beneficial impact of RIPC on renal functional preservation from the biomarker standpoint, we have observed a possible hint of its renoprotective effect on histological grounds. This was reflected by a slightly reduced mean infarct area in the RIPC + PN group when compared to the PN group alone. On the other hand, the zone of ischemia, the region between infarcted and unaffected kidney parenchyma was thicker in the former animals which could be explained due to the area protected from complete necrosis being added to ischemic zone. However, these alterations were not found significant statistically. Both groups had similar regeneration capacity as noted by the same Ki-67 proliferative indices.

\section{Conclusion}

According to the results of this experimental study, RIPC failed to counteract the renal functional consequences of PN under warm ischemia in a solitary kidney model. Similarly, benefits at the tissue level were vague and did not appear significant. Our cumulative results via biochemical and histological analyses were not concordant with the renoprotective effect of RIPC.

\section{Abbreviations}

IPC: Ischemic preconditioning; RIPC: Remote ischemic preconditioning; PN: Partial nephrectomy; KIM-1: Kidney injury molecule; IL: Interleukin; NGAL: Neutrophil Gelatinase-Associated Lipocalin; AKI: Acute kidney injury; WIT: Warm ischemia time

\section{Acknowledgements \\ - Abstract of this study was accepted for poster presentation at the 2020 Annual Meeting of the European Association of Urology. \\ - We'd like to express our sincere gratitude to Ahmet Kocabay, who helped us with all aspects of the experimental procedures.}

Financial disclosures

None.

Consent to participate

Not Applicable.

\section{Authors' contributions}

TTM: Generation of the hypothesis, experimental (animal laboratory) procedures, data acquisition, data analysis and interpretation, drafting of the manuscript, ÖA: Experimental (animal laboratory) procedures, data acquisition, data analysis and interpretation, critical analysis and revision of the manuscript, AA: Histopathological assessment of tissue specimens, SI: Immunohistochemical and biochemical analyses in biological specimens, AU: Data analysis and interpretation, LAE: Experimental (animal laboratory) procedures, data acquisition, perioperative care of study subjects, MÖ: Experimental (animal laboratory) procedures, data acquisition, perioperative care of study subjects, ACT: Experimental (animal laboratory) procedures, perioperative care of study subjects, DEB: Histopathological assessment of tissue specimens, critical analysis and revision of the manuscript, MK: Critical analysis and revision of the manuscript, supervision and mentorship, TE: Critical analysis and revision of the manuscript, supervision and mentorship. All authors have read and approved the final version of the manuscript.

\section{Funding}

We acknowledge support by the Open Access Publication Funds of the University of Göttingen.

\section{Availability of data and materials}

All data generated or analyzed during this study are included in this published article. The raw data can be found on https://osf.io/3h4p6/?view_ only=8fa3e35c908741 bd8ae4cef4dac13951.

\section{Declarations}

Ethics approval and consent to participate

Koç University Local Ethics Committee for Animal Experiments (Approval no: 2015-19).

\section{Consent for publication}

Not Applicable.

\section{Competing interests \\ None.}

\section{Author details}

'Department of Urology, University Medical Center Göttingen, Robert-Koch Straße 40, 37075 Göttingen, Germany. ${ }^{2}$ Department of Urology, Koc University School of Medicine, Istanbul, Turkey. ${ }^{3}$ Department of Pathology, 
Koc University School of Medicine, Istanbul, Turkey. ${ }^{4}$ Department of Biochemistry, Koc University Hospital, Istanbul, Turkey. ${ }^{5}$ Koc University School of Medicine, Istanbul, Turkey. ${ }^{6}$ Koc University, Center for Translational Medicine (KUTTAM), Istanbul, Turkey. ${ }^{7}$ Department of Internal Medicine, Division of Nephrology, Koc University School of Medicine, Istanbul, Turkey. ${ }^{8}$ Department of Urology, VKF American Hospital, Istanbul, Turkey.

Received: 6 July 2020 Accepted: 14 April 2021

Published online: 16 July 2021

\section{References}

1. Ljungberg B, Albiges L, Abu-Ghanem Y, Bensalah K, Dabestani S, FernándezPello $S$, et al. European Association of Urology guidelines on renal cell carcinoma: the 2019 update. Eur Urol. 2019;75(5):799-810. https://doi.org/1 0.1016/j.eururo.2019.02.011

2. Thompson RH, Lane BR, Lohse CM, Leibovich BC, Fergany A, Frank I, et al. Every minute counts when the renal hilum is clamped during partial nephrectomy. Eur Urol. 2010;58(3):340-5. https://doi.org/10.1016/j.eururo.201 0.05.047.

3. Cochrane J, Williams BT, Banerjee A, Harken AH, Burke TJ, Cairns CB, et al. Ischemic preconditioning attenuates functional, metabolic, and morphologic injury from ischemic acute renal failure in the rat. Ren Fail. 1999;21(2):135-45. https://doi.org/10.3109/08860229909066978.

4. Reimer KA, Murry CE, Yamasawa I, Hill ML, Jennings RB. Four brief periods of myocardial ischemia cause no cumulative ATP loss or necrosis. Am J Phys. 1986;251(6 Pt 2):H1306-15. https://doi.org/10.1152/ajpheart.1986.251.6.H1306.

5. Murry CE, Jennings RB, Reimer KA. Preconditioning with ischemia: a delay of lethal cell injury in ischemic myocardium. Circulation. 1986;74(5):1124-36. https://doi.org/10.1161/01.cir.74.5.1124.

6. Wever KE, Menting TP, Rovers M, et al. Ischemic Preconditioning in the Animal Kidney, a Systematic Review and Meta-Analysis. Eltzschig HK, ed. Plos One. 2012;7(2):e32296. https://doi.org/10.1371/journal.pone.0032296.

7. Kharbanda RK, Nielsen TT, Redington AN. Translation of remote ischaemic preconditioning into clinical practice. Lancet Lond Engl. 2009;374(9700): 1557-65. https://doi.org/10.1016/S0140-6736(09)61421-5.

8. Toosy MM, Grace M. Ischaemic preconditioning protects the rat kidney from reperfusion injury: ISCHAEMIC PRECONDITIONING PROTECTS THE RAT KIDN EY. BJU Int. 2001;84(4):489-94. https://doi.org/10.1046/j.1464-410x.1999.001 72.x.

9. Orvieto MA, Zorn KC, Mendiola FP, Gong EM, Lucioni A, Mikhail AA, et al. Ischemia preconditioning does not confer resilience to warm ischemia in a solitary porcine kidney model. Urology. 2007;69(5):984-7. https://doi.org/1 0.1016/j.urology.2007.01.100.

10. Huang J, Chen Y, Dong B, Kong W, Zhang J, Xue W, et al. Effect of remote ischaemic preconditioning on renal protection in patients undergoing laparoscopic partial nephrectomy: a 'blinded' randomised controlled trial. BJU Int. 2013;112(1):74-80. https://doi.org/10.1111/bju.12004.

11. Bedir S, Ma Y, Antonelli J, Cadeddu JA, Gahan JC. Ineffectiveness of remote ischemic renal preconditioning in a porcine solitary-kidney model. J Endourol. 2015;29(5):590-4. https://doi.org/10.1089/end.2014.0563.

12. Endre ZH, Pickering JW, Walker RJ, Devarajan P, Edelstein CL, Bonventre JV, et al. Improved performance of urinary biomarkers of acute kidney injury in the critically ill by stratification for injury duration and baseline renal function. Kidney Int. 2011;79(10):1119-30. https://doi.org/10.1038/ki.2010.555.

13. Han WK, Bailly V, Abichandani R, Thadhani R, Bonventre JV. Kidney injury Molecule-1 (KIM-1): a novel biomarker for human renal proximal tubule injury. Kidney Int. 2002;62(1):237-44. https://doi.org/10.1046/j.1523-1755.2 002.00433.x

14. Mishra J, Ma Q, Prada A, Mitsnefes M, Zahedi K, Yang J, et al. Identification of neutrophil gelatinase-associated lipocalin as a novel early urinary biomarker for ischemic renal injury. J Am Soc Nephrol JASN. 2003;14(10): 2534-43. https://doi.org/10.1097/01.asn.0000088027.54400.c6.

15. Mårtensson J, Martling C-R, Bell M. Novel biomarkers of acute kidney injury and failure: clinical applicability. Br J Anaesth. 2012;109(6):843-50. https:// doi.org/10.1093/bja/aes357.

16. Chen W-Y, Li L-C, Yang J-L. Emerging Roles of IL-33/ST2 Axis in Renal Diseases. Int J Mol Sci. 2017;18(4). doi:https://doi.org/10.3390/ijms18040783

17. Lanaspa MA, Ishimoto T, Cicerchi C, Tamura Y, Roncal-Jimenez CA, Chen W, et al. Endogenous fructose production and fructokinase activation mediate renal injury in diabetic nephropathy. J Am Soc Nephrol JASN. 2014;25(11): 2526-38. https://doi.org/10.1681/ASN.2013080901.
18. Levey AS, Bosch JP, Lewis JB, Greene T, Rogers N, Roth D. A more accurate method to estimate glomerular filtration rate from serum creatinine: a new prediction equation. Modification of diet in renal disease study group. Ann Intern Med. 1999;130(6):461-70. https://doi.org/10.7326/0003-4819-130-6-1 99903160-00002.

19. Go AS, Chertow GM, Fan D, McCulloch CE, Hsu C. Chronic kidney disease and the risks of death, cardiovascular events, and hospitalization. N Engl J Med. 2004;351(13):1296-305. https://doi.org/10.1056/NEJMoa041031.

20. Shekarriz B, Shah G, Upadhyay J. Impact of temporary hilar clamping during laparoscopic partial nephrectomy on postoperative renal function: a prospective study. J Urol. 2004;172(1):54-7. https://doi.org/10.1097/01.ju. 0000132125.78189.93.

21. Funahashi Y, Hattori R, Yamamoto T, Kamihira O, Kato K, Gotoh M. Ischemic renal damage after nephron-sparing surgery in patients with normal contralateral kidney. Eur Urol. 2009;55(1):209-15. https://doi.org/10.1016/j. eururo.2008.07.048.

22. Desai MM, Gill IS, Ramani AP, Spaliviero M, Rybicki L, Kaouk JH. The impact of warm ischaemia on renal function after laparoscopic partial nephrectomy. BJU Int. 2005;95(3):377-83. https://doi.org/10.1111/j.1464-41 0X.2005.05304.x.

23. Lifshitz DA, Shikanov S, Jeldres C, Deklaj T, Karakiewicz PI, Zorn KC, et al. Laparoscopic partial nephrectomy: predictors of prolonged warm ischemia. J Urol. 2009;182(3):860-5. https://doi.org/10.1016/j.juro.2009.05.039.

24. Godoy G, Ramanathan V, Kanofsky JA, O'Malley RL, Tareen BU, Taneja SS, et al. Effect of warm ischemia time during laparoscopic partial nephrectomy on early postoperative glomerular filtration rate. J Urol. 2009;181 (6):2438-43; discussion 2443-2445. https://doi.org/10.1016/j.juro.2009.02.026.

25. Abdeldaeim HM, Abou Youssif TM, Abdel Wahab MM, Kotb AF, OF EG, Mokhless IA. Prospective randomized comparison between cold and warm ischemia in patients with renal insufficiency undergoing partial nephrectomy. Urology. 2015;85(4):862-8. https://doi.org/10.1016/j.urology.2 014.11.046.

26. Huang C-H, Lai C-C, Yang A-H, Chiang S-C. Myocardial preconditioning reduces kidney injury and apoptosis induced by myocardial ischaemia and reperfusion. Eur J Cardio-Thorac Surg Off J Eur Assoc Cardio-Thorac Surg. 2015;48(3):382-91. https://doi.org/10.1093/ejcts/ezu453.

27. Hladunewich MA, Corrigan G, Derby GC, Ramaswamy D, Kambham N, Scandling JD, et al. A randomized, placebo-controlled trial of IGF-1 for delayed graft function: a human model to study postischemic ARF. Kidney Int. 2003;64(2):593-602. https://doi.org/10.1046/j.1523-1755.2003.00100.x.

28. Lewis J, Salem MM, Chertow GM, Weisberg LS, McGrew F, Marbury TC, et al. Atrial natriuretic factor in oliguric acute renal failure. Anaritide Acute Renal Failure Study Group. Am J Kidney Dis Off J Natl Kidney Found. 2000;36(4): 767-74. https://doi.org/10.1053/ajkd.2000.17659.

29. Coca SG, Yalavarthy R, Concato J, Parikh CR. Biomarkers for the diagnosis and risk stratification of acute kidney injury: a systematic review. Kidney Int. 2008;73(9):1008-16. https://doi.org/10.1038/sj.ki.5002729.

30. Yoon YE, Lee KS, Choi KH, Kim KH, Yang SC, Han WK. Preconditioning Strategies for Kidney Ischemia Reperfusion Injury: Implications of the "TimeWindow" in Remote Ischemic Preconditioning. Marson L, ed. Plos One. 2015;10(4):e0124130. https://doi.org/10.1371/journal.pone.0124130.

\section{Publisher's Note}

Springer Nature remains neutral with regard to jurisdictional claims in published maps and institutional affiliations.

Ready to submit your research? Choose BMC and benefit from:

- fast, convenient online submission

- thorough peer review by experienced researchers in your field

- rapid publication on acceptance

- support for research data, including large and complex data types

- gold Open Access which fosters wider collaboration and increased citations

- maximum visibility for your research: over $100 \mathrm{M}$ website views per year

At $\mathrm{BMC}$, research is always in progress.

Learn more biomedcentral.com/submissions 